http://www.jfas.info

\title{
THE ROLE OF INTEREST, SELF-EFFICACY AND ACADEMIC SELF-REGULATION IN PREDICTING ACADEMIC ACHIEVEMENT OF STUDENTS OF ISLAMIC AZAD UNIVERSITY
}

\author{
F. Yahyazadeh ${ }^{1}$ and M. Mohammadipour ${ }^{2, *}$ \\ ${ }^{1}$ Department of Counseling, Quchan Branch, Islamic Azad University, Quchan, Iran \\ ${ }^{2}$ Department of Psychology, Quchan Branch, Islamic Azad University, Quchan, Iran
}

Published online: 15 June 2016

\begin{abstract}
The purpose of this study is analyzing the role of self-regulation (memory strategies, goal setting, self-evaluation, help finding, the environment structure, learning commitment, organizing), interest (focus, satisfaction, confidence, communication) and self-efficacy in predicting academic achievement of students. Therefore, 265 post-graduate student of counseling major who were studying in second semester of 2014 were selected through cluster sampling and a Motivational Strategies Learning (MSLQ) test, interest and self-regulation were conducted on them. The results showed that among subtests of academic self-regulation, only subtest of self-evaluation has ability to predict academic achievement and among subtests of interest only subtests of confidence has ability to predict academic achievement, but self-efficacy is not able to predict students' progress.
\end{abstract}

Author Correspondence, e-mail: mmohamadipoor@yahoo.com doi: http://dx.doi.org/10.4314/jfas.v8i2s.166 
Also by using structural equation modeling it showed that there is no direct and indirect significant relationship between interest, self-efficacy and self-regulation. Using adapting model criteria, the conceptual model is consistent with the measurement model.

Keywords: Interest; self-regulation; self-efficacy; academic achievement.

\section{INTRODUCTION}

One of the main purposes of the educational system and especially is the universitiesis educating independent staff. It is expected that students act as experts in related areas. In the framework of psychological concepts such as self-regulation and motivational beliefs in academic achievement is important (Kareshki, 2011).

Some of the factors that had an impact on a lot of research on the academic achievement of learners are variables such as interest, self-regulation, self-efficacy, learner emotions, and individual autonomy in learning and learner structure of goal setting (Newbell, 2003). Reviewing researches of this field reflects the impact of these variables on academic achievement.

Students' individual differences in terms of educational achievement and the factors affecting it, including issues that have always attracted the attention of trainers, teachers and experts of training psychology. But academic achievement is not affected by a number of factors such as the scholastic aptitude (Lawlroigen, 1997). Academic self-efficacy (Karimzadeh, 2006), educational methods (Samadi, 2007), motivational beliefs (Kajbaf, 2003), emotional intelligence and creativity (Sharifi, 2010) are effective. The fact is that these factors and variables are so intertwined and have mutual interact with each other that it makes difficult determining the role and contribution of them, however, research shows that among these factors, training and personal factors with cognitive and social nature, have the greatest impact on academic achievement (Seyf, 2007).

Zimmerman and Pons (1988) in a study entitled differences in students' self-regulated learning strategies have shown a significant relationship between academic achievement and self-regulated learning strategies and the correlation between success in mathematics performance and using self-regulated learning strategies was 0.41. Especially math 
performance is more closely related with reviewing tips strategy and it is less related with strategies of asking help from adult. Academic self-regulation is a powerful predictor of academic achievement (Zimmerman, 1990). It represents active and systematic efficiency to achieve the scientific goals (Zimmerman, 2000). When students are highly motivated they have more effective academic self-regulation (Zimmerman and Shank, 2008).

Among cognitive motivational structures, it has proven that academic self-efficacy has especial vital role in the success of self-regulation in learning process (Zimmerman and Shank, 2008). Self-efficacy refers to the subjective belief that can successfully execute the required behavior to achieve the desired result (Bandura, 1997). Academic self-efficacy in particular refers to the students believe that they can successfully carry out a scientific project at an optimum level (Shank, 1991). Academic self-efficacy is known as a strong predictor for wide range of academic performance (Moulton, Lent, 1991, Shank, 2005). It also has a close relationship with academic self-regulation, so that students have better performance with strong self-efficacy beliefs (Bandura, 1991; Shank, 2005). Goal setting is a very important link which ties the academic self-regulation and academic achievement with academic success (Locke and Latham, 2002; Zimmerman and Bandura, 1994). Wood and Locke (1998) showed that academic self-efficacy is related to academic performance not only directly but also indirectly affect academic goals through mediating.

Personal interest in specific areas of activity can increase or decrease the self-monitoring performance independent of the effects of or self-motivational goals. Recently some efforts have directly been created to generate interest in academic self-regulation model. However, in many of these studies, interest is observed as a purpose or result of the trend or disciplinary result rather than a facilitator is. Based on documentary evidence of the independent role of cognitive motivation (Ahmed et al., 2013), we assume that individual interest is an important facilitator of self-motivation and success in terms of academic self-regulation.

Interest and study willingness are issues that concern the science successors. Researchers are always seeking ways to set and select the destination to maximize their abilities and thereby answer their mental and emotional needs. Therefore it could be stated that educational interest is one of the pillars of progress on a personal and macro level and in the communities. In a 
way that positive and negative effects of this issue is quite clear and palpable. If studying is out of interest it will be the cause of develop and propensity of community and if there is lack of interest in education, it is evident that it will have negative effects, thus academic issues are important and influential that need more attention from individual understanding, family and society (Amraei, 2004).

When students use series of self-regulation skills such as memory strategies, goal setting, self-evaluation, help finding, environment structure, learning responsibility, planning and organizing, they have a successful academic performance (Magno, 2011).

Mostafaei (2010) conducted a research about self-regulated learning and academic performance using correlation method andconcluded that there is positive correlation between self-regulated learning and academic performance. Also Zimmerman and Pons (1998) in a study found that the ability of self-regulation can predict self-efficacy in achieving academic goals, self-assessment standards and also final scores of the course.

According to previous studies it seems that self-efficacy is effective in learning and development and plays an important role in high academic achievement. Overall, the empirical evidence indicates that there is a relationship between self-efficacy and academic achievement. Bandura in a series of studies found that the beliefs of self-efficacy of student compared to regulating academic activities is a strong predicted of goals and academic achievement (Farahani, 2002). According to Bandura's social cognitive theory (1997) and several other studies, including Pajars and Miller (1994 and 1997); Pajars and Graham (1999); Green, Miller, Krason, Duke, Kay (2004), Kabiri (2003 ), Karimzadeh (2006) self-efficacy as an important factor play a leading role in predicting academic achievement at different educational levels.

Another important and affecting factor of academic achievement is academic interest. Seyf (2001), in a book of educational psychology, according to Klay Patrick (199q) quoted Enders (1998) that learning in schools must be target based and purposeful learning is possible through the ways of getting students to do projects of interest of a better choice. Bloom (1968), in a book of "Human features and academic learning" mentioned the emotional input behaviors or interest and motivation in academic achievement, as 25\% (Rezaei, 2005). 


\section{METHODOLOGY}

The study is descriptive and correlational type. Because in this study the relationships between variables is based on structural equations in a form of causal model has been investigated. The statistical population of study is consisted of all post-graduate students of Counseling major of Islamic Azad University of Quchan in the second semester of 2014. The total statistical population is 815 students (school counseling major 205 students, family counseling 247 students, rehabilitation counseling 191 students and career counseling 172 students). The reason for choosing post graduate students of counseling major was similar nature of courses and learning and identical motivational strategies of these majors. And due to the fact that the maximum number of questions per questionnaire is 13 , so the minimum sample size for factor analysis or causal model is 260 . Also the number of variables in the conceptual model is 15 variables and the minimum number of participants is 300 people. Considering the minimum sample according to the number of questions, is 260, therefore among students who had research methodology course in the second semester of 2014, 260 students were selected by cluster sampling method. The sampling unit was a class and from each major, at least one class randomly was selected but due to the relatively high number of students in family and school major, two classes were selected from each major but from students of rehabilitation and career major, one class was selected from each one. The questionnaires were conducted on six classes a on the total number of 270 , but some questionnaires were incomplete and 255 were collected. Motivation strategies of learning, interest and self-regulation questionnaires were used for collecting data.

Motivational strategies learning questionnaire (MSLQ) have been developed by Pinternech et al (1991) to measure learning strategies and motivational beliefs. The questionnaire has 80 -items included two motivational beliefs scale (30 items) and learning strategies (50 items). The scale of motivational beliefs includes 3 subtests; task value, expectations and emotional components. Scale of learning also includes two subscales strategies of meta-cognitive and resources management. The questionnaire questions has 5 choices, and participants should respond based on a Likert scale of 5 degrees $(1=$ is not true about me at all to $5=$ completely 
true in my case). Sohrabi (2009) to determine the reliability of learning strategies used Cronbach's alpha and split in two halves that for the entire questionnaire and reliability respectively was 0.95 and 0.85 , which represents the reliability of the questionnaire of learning strategies.

Course interest survey (CIS) was designed by Kloro Sobia in 1993 with 34 items and four subtests. These subtests are: subscale of attention, relevance, confidence and satisfaction. This tool has been formulated based on five-point Likert scale, to any positive item for "totally agree" has point 5 and for other choices there are "agree", "no idea", "disagree" and "strongly disagree", $4,3,2$, and 1 point is given.In the process of scoring balls, for a negative item the choice of "totally agree" has one point. And other choices in order "agree 2 pints", "no idea 3 pints ", "disagree 4 pints" and "completely disagree 5 points". In Ghaznavi (2007) research validity and reliability that have been approved are as follows:

Table 1. Reliability coefficient of interest questionnaire

\begin{tabular}{cccccc}
\hline Subtests & Interest & Relevance & Confidence & Satisfaction & Total score \\
\hline Reliability & 0.9168 & 0.8747 & 0.8710 & 0.8680 & 0.9312 \\
\hline
\end{tabular}

Academic self-regulation questionnaire (AS-R) has been developed by Magno in 2010 to measure students' self-regulation. This questionnaire has 55 questions and 7 subtests as: memory strategies (14 items), goal setting (5 items), and self-evaluation (12 items), seek help (8 items), the environment (5 items), learning responsibility (5items), planning and organizing (6 items). Each question has four options (strongly agree, agree, disagree, strongly disagree) and respondents should select the one that is close to his idea. Magno $(2010,2011)$ to estimate the predictive validity of the questionnaire used academic achievement of students of University of the Philippines as a benchmark. The questionnaire was performed on 2055 and 755 students, and seven factors using principal components analysis with Varimax rotation was extracted. Seven subtests scales predict $42.52 \%$ of total variance of academic performance and load factor of all 7 factors is more than 0.4. Also the correlation of all 7 subtests with each other in 0.01 levels is meaningful and according to fitness model, the factor 
structure of academic self-regulation is approved.

\section{FINDINGS}

To predict the academic achievement of academic self-regulation variables (memory strategies, goal setting, self-evaluation, help-finding, environmental structure, learning and organizing responsibility), interest (attention, relevance, confidence and satisfaction) and self-efficacy, a conceptual model is presented by structural equations modeling were tested. In the current research interest (attention, relevance, reliability satisfaction) and self-efficacy as an exogenous variable, academic self-regulation (memory strategies, goal setting, self-evaluation, help-finding, environmental structure, learning and organizing responsibility) and academic achievement as endogenous variables of the model. The present study has been previously tested in the following models:

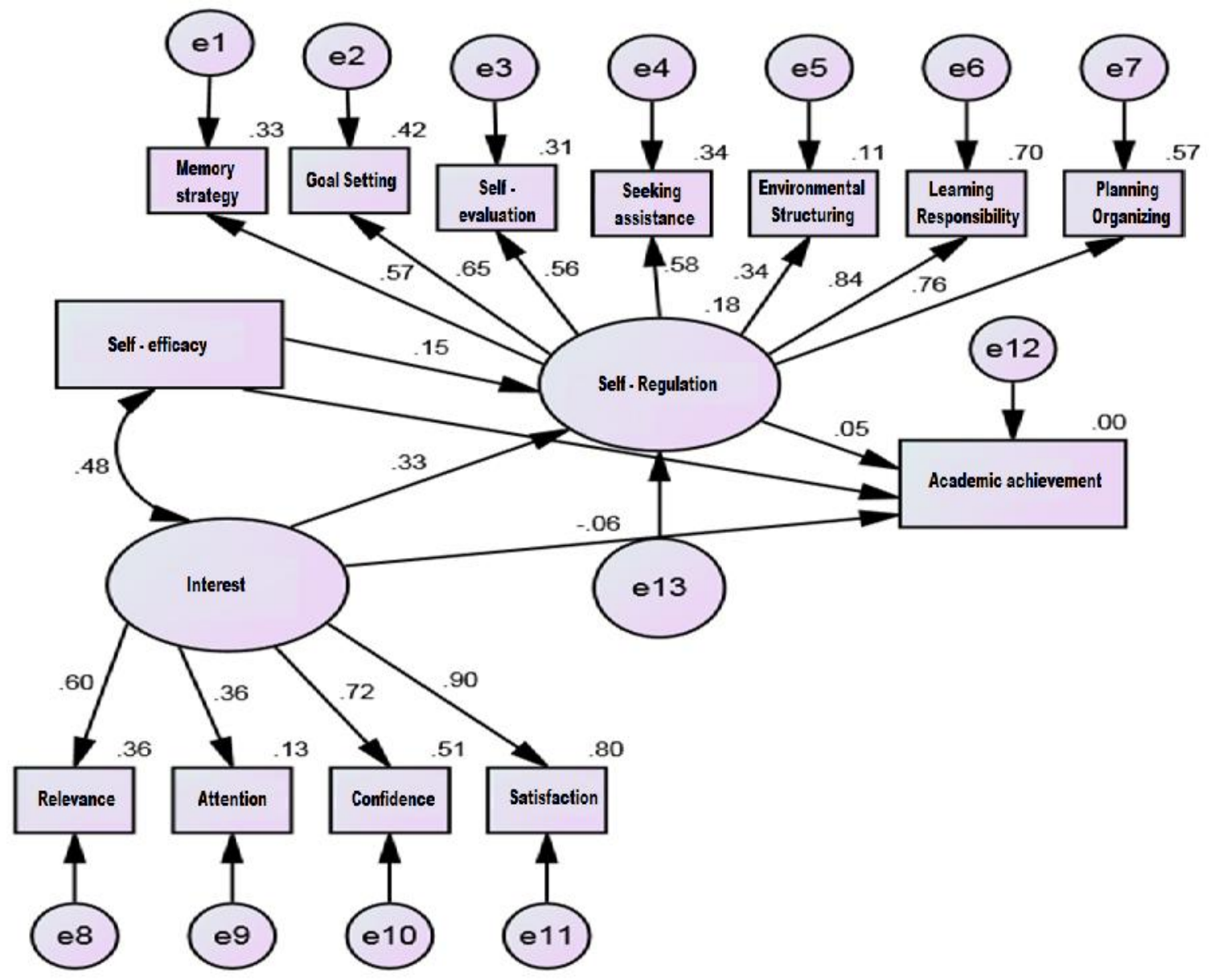

Fig.1. A tested version of current study 
In the figure above a tested version of current study with coefficients of standard path were shown. Also in the table below, coefficients of direct effects significant levels of pathways have been reported.

Table 2. Standard coefficients to estimate the direct effects

\begin{tabular}{cccccccc}
\hline $\begin{array}{c}\text { Criterion } \\
\text { variable }\end{array}$ & Pathways & $\begin{array}{c}\text { Predictor } \\
\text { variable }\end{array}$ & Estimate & S.E. & C.R. & P & Label \\
\hline $\begin{array}{c}\text { Self- } \\
\text { regulative }\end{array}$ & $\leftarrow$ & self-efficacy & .152 & .075 & 1.624 & .104 & No effect \\
\hline $\begin{array}{c}\text { Self- } \\
\text { regulative }\end{array}$ & $\leftarrow$ & Interest & .335 & .114 & 3.062 & .002 & Effective \\
\hline $\begin{array}{c}\text { Academic } \\
\text { achievement }\end{array}$ & $\leftarrow$ & Self-regulation & .053 & .043 & .557 & .577 & No effect \\
\hline $\begin{array}{c}\text { Academic } \\
\text { achievement }\end{array}$ & $\leftarrow$ & self-efficacy & .003 & .033 & .035 & .972 & No effect \\
\hline $\begin{array}{c}\text { Academic } \\
\text { achievement }\end{array}$ & $\leftarrow$ & Interest & -.055 & .049 & -.524 & .600 & No effect \\
\hline
\end{tabular}

The results of the table above show that:

1- Self-efficacy with coefficient of (0.152) has no direct effect on academic self-regulation. Since its significance level $(0.104)$ is more than 0.05 . Therefore research hypothesis is rejected with $95 \%$ confidence.

2- Interest with coefficient of (0.335) has direct effect on academic self-regulation. Since its significance level (0.002) is less than 0.05. Therefore research hypothesis is confirmed with $95 \%$ confidence.

3- Self-regulation with coefficient of (0.053) has no direct effect on academic achievement. Since its significance level $(0.577)$ is more than 0.05 . Therefore research hypothesis is rejected with $95 \%$ confidence. 
4- Self-efficacy with coefficient of (0.003) has no direct effect on academic achievement. Since its significance level $(0.972)$ is more than 0.05 . Therefore research hypothesis is rejected with $95 \%$ confidence.

5- Interest with coefficient of (-0.055) has no direct effect on academic achievement. Since its significance level (0.600) is more than 0.05. Therefore research hypothesis is rejected with $95 \%$ confidence.

One of the features of structural equation modeling is to estimate the indirect effects of variables on each other. This feature allows researchers to examine the role of mediator variables in the model. The present study is seeking to investigate the mediator role of academic self-regulation in the relationship between academic self-efficacy and interest of academic achievement which table below shows standard coefficients of indirect impact on educational achievement:

Table 3. Analyzing indirect effects or the role of mediator variables

\begin{tabular}{cccc}
\hline $\boldsymbol{\bullet}$ & self-efficacy & Interest & Self-regulation \\
\hline Self-regulation & 0.000 & 0.000 & 0.000 \\
\hline $\begin{array}{c}\text { Academic } \\
\text { achievement }\end{array}$ & 0.008 & 0.018 & 0.000 \\
\hline
\end{tabular}

According to the indirect effects of variables it can be stated that self-efficacy with coefficient of (0.008) and interest with coefficient of (0.018) has indirect impact on academic achievement. According to the criteria that Giffen et al (2000) have proposed, a total model has good fitting with the collected data.

Table 4. Indexes of overall fitting of tested model study

\begin{tabular}{lllllll}
\hline RMSEA & AGFI & GFI & CFI & X2/D.F & D.F & $X^{2}$ \\
\hline $0 / 07$ & $0 / 847$ & $0 / 898$ & $0 / 915$ & $1 / 813$ & 61 & $110 / 588$ \\
\hline
\end{tabular}

According to the fitted indicators in the table above, an overall result can be achieved the 
conceptual model based on a comprehensive study of theoretical and practical background was designed by researcher is consistent with collected data and in fact, the overall model of study is supported by the data and statistical methods were used to test it.

\section{DISCUSSION}

The relationship between academic self-regulation (memory strategies, goal setting, self-evaluation, help-finding, environmental structure, learning and organizing responsibility) and academic achievement of students, academic self-regulation is a significantly predict academic achievement $(B=0.246), p<0 / 009$.

As it was mentioned above, the results suggests that when the classroom environment is enjoyable, challenging content, and students have more choice and interest, goal orientation is dominant, and the motivational beliefs (self-efficacy and intrinsic value) and self-regulation will be better. An environment in which a person based on his preferences and interests explore the issues and the course of the study, is providing an enjoyable learning experiences, leading to their involvement in the learning process and an effective learning activities and orientation of dominant goals and intrinsic motivation in students that is a strong predictor of academic achievement (Tapola, 2008, Turner, 2002).

In a similar study, Garcia and Pintrich (1996) to examine the effects of self-motivation and performance have reached similar conclusions. Students who found school environment self-autonomy supportive and were allowed to make decision had reported higher levels of motivation, and their self-efficacy and task value beliefs were at a higher level.

The findings were also consistent with Politer et al (2002). According to their conclusions, the pro-autonomy environment compared to control over the environment, are tending to improve their internal motivation. The findings of research are consistent with studies on the role of teacher behavior and their self-regulation behaviors and adaptive beliefs (Deci et al. 1981, Rio 1998, Ryan and Gronlik 1986, Valerand et al. 1997).

Therefore major research has been done on the relationship between environmental perceptions and self-regulation is consistent with our findings and this is due to the significance of environmental perceptions in self-regulation. These relationships in different 
cultural contexts have same results. Therefore, it is a relatively broad context. In general providing opportunities in the classroom and giving the right to choose teaching as a motivational tool that encourages students in the process of learning provide meaningful learning rather than rote learning. Thus providing opportunities for students to choose activities and learning experiences based on their areas of interest by using their own preferred learning styles to enhance performance and students' self-confidence should be confirmed.

The relationship between interest (attention, relevance, confidence and satisfaction) and academic achievement of students, interest significantly predict academic achievement (B $=0.159), \mathrm{p}<0 / 009$. These findings were consistent with Attarpour (2001), Nasiri (2000), Soltani et al (2000) and Motaghi (1997). Many research results show that there is a direct and positive relationship between interest and academic achievement. Thus, by integrating and combining the results of research, it can be concluded that there is relationship between interest and academic achievement. These findings confirm the Patrick (1999) claims that: If students do their favorite projects, target-learning is more possible. Also Clock (1990) in his study showed that acquiring a skill enhance the interest and thereby lead to academic achievement and learning will be continuous and stable. Also according to the results of Talebzade (1999) it can be mentioned that students with no interest in education are faced with lack of incentives, such as academic achievement. As a result, they fall behind in school and have academic failure.

On the relationship between self-efficacy and academic achievement, self-efficacy is not predicting academic achievement significantly $(\mathrm{B}=0.087), \mathrm{p}<0 / 009$. These results are not consistent with Parvin (1995), Pajares and Miller (1994), Pajares (1997) and Bendura (1997). In studies of Abdinia (1998), Kaviani (2005), Karimzadeh (2006) and Zeinalipour et al (2009) have done, it was realized that self-efficacy has important role in academic performance. And students, who have high self-efficacy in comparison with low self-efficacy students, achieve more development. Therefore providing proper context for the emergence of positive efficacy could be the groundwork for future academic success.

Based on the theoretical foundations and available research, people with high self-efficacy in 
various fields of activities are using self-control as an aspect of metacognitive knowledge. Researches have shown that students with high self-efficacy use metacognitive abilities more than others (Vanga et al., 2008). Unfortunately our findings are not consistent with Pakmehr, Kareshki (2011), Vanga et al (2008) and Kamali et al (2006). These results are not consistent with theoretical and research foundations. All researches, including Kamali et al (2006), Antonio Zhafiano et al. (2013), and Wolters (2004), Elliot et al (1999) concluded that self-efficacy and task value are the predictors of self-regulation. But the results are not consistent with the findings of the above-mentioned research. Several reasons can be the cause of such an outcome. Perhaps one of the most important reasons is that 40 percent of sample studies are post-graduate students with relatively high average age and most of them have come not to comprehension but to obtain a degree. On the other hand, most humanities students are not interested in courses of statistics and research methodology and often low self-efficacy courses are not important for them. Thus in such circumstances intrinsic and self-efficacy variables are not good predictor of academic achievement. The result of our research is just consistent with the result of research of Li and Libong (2014). They conclude that high academic achievement is dependent on self-efficacy and strong interest of people to the course subject. Academic self- efficacy and personal interest are respectively appearing as a key component in understanding and direction effective path of the academic achievement. Self-efficacy has no direct impact on student achievement, but through score it has.

The most important limitation of the study is little control because it was a correlational research. The lack of gender control, academic, economic and social situations in conceptual model of the study, the statistical population is just limited to students of the Human Sciences, Islamic Azad University of Quchan, so we should follow a precautionary measure to generalize the findings to other university students. Measuring hidden and obvious variables have been conducted by using self-report questionnaires, while deeper information will be obtained through structured interviews, tracking methods and measuring thinking aloud. In this study, we cannot reach to a definite causal relationship in the presented conceptual model. The reason is that the casual model (structural equation modeling and path analysis) is only examining the relationships between variables. 


\section{REFERENCES}

[1] Kareshki, Hossein Mohseni, Nickchehreh, (2012). Motivation in teaching and learning (theory and applications), the first edition. Tehran: AVAYE NOUR.

[2] Newbel, M. (2003), Learning and teaching support, Journal of Educational Sychology, Vol. 96, No. 3, pp. 468-483.

[3] Farmahini Farahani, Mohsen; Abdolmalei, Jamal; Rashidi Zahra (2007). The relationship between emotional intelligence, self-regulation strategies and targets middle-class progress in the first grade students in city Qorveh, bimonthly Journal of Behavior, 15.

[4] Abdolmaleki Jamal, Yousefi Afrashteh, Majid, Rashidi Zahra, Abdolmaleki Saber, Mohammadi Noushirvan, Siami Leyla (2008) Design and Assessment of Educational Progress causal model analysis method of perception of parents and academic motivation and academic achievement, family and Research Quarterly, Issue 4, pp. 47-72.

[5] Karim Zadeh, M. (2006). The relationship between academic self-efficacy and academic achievement in high school female students in Tehran. Women's Studies, Issue II. Summer 85 .

[6] Samadi, Masoumeh (2007). Trainings and educational self-regulation effect on academic achievement. New cognitive science. 9 (1), pp. 40-48.

[7] Kajbaf, MB, Rumi, Molavi Hussain, and Shirazi Tehrani, Alireza (2003). The relationship between self-regulated learning strategies and motivational beliefs of the student's academic performance. New Cognitive Science, Volume 5, Number 1, pp. 27-33.

[8] Sharifi, nastaran (2010). Development of structural models for predicting academic achievement based on intelligence, creativity, and emotional intelligence at different levels of education. The thesis of PHD.

[9] Seyf Ali Akbar, (2007). Modern educational psychology, Tehran: DORAN Publication

[10]Zimmerman, B. Y. \& Pons, M. (1988). Construct education of a student self-regulated learning Journal of Educational psychology. No, 80, 118-124. 
[11]Zimmerman. B. Y. (1990). Self-regulated learning and academic learning achievement: The emergence of a social cognitive perspective educational psychology review, 2, 173-201.

[12]Zimmerman, B. J. (2000). Self-efficacy: An essential motive to learn. Contemporary educational pysychology 25.82-91.

[13]zimmeman, B \& Schunk, D (2008). Motivtion: An essential dimension of self-regulated learning.In D.H schunk \& B.J.Zimmerman, motivation and self-regulated learning: Theory, and application (pp. 1-30).Mahwah, NJ: Erlbaun.

[14]Bandura, A. (1997). Self-efficacy: the exercise of control. New York. W. H. freeman.

[15]Bandura, A. (1997). Self-efficacy: the exercise of control. USA: Englewood-cliffs, NJ: prentice hall.

[16]Schunk, D. H. (1991). Self-efficacy and academic motivation. Educational Psychologist, $26,207-231$.

[17]Multon, Karen D.; Brown, Steven D.; Lent, Robert W. Relation of self-efficacy beliefs to academic outcomes: A meta-analytic investigation. Journal of Counseling Psychology, Vol 38(1), Jan 1991, 30-38

[18]Zimmerman, B. Y. (1994). Dimensions of academic self-regulation: A conceptual frame work education. In. O. H. Schunk \& B. Y. Zimmerman (EDS), self-regulation of learning and performance: Issues and education applications (pp. 3-21).

[19] Ahmed Hassan Hemdan Mohamed (2013).The Relationship BetweenMetacognition and Self-regulation in Young Children.

[20]Magno, C. (2011b). Validating the academic self-regulated learning scale with the motivated strategies for learning questionnaire (MSLQ) and learning and study strategies inventory (LASSI), the international journal of educational and psychological assessment. $\operatorname{vol~7(2),~56-72.~}$

[21]Mostafaei, Ali. (2010). The effectiveness of the training components of self-regulated learning strategies based on model pintrych based on self-efficacy locus control and 
academic performance of students of third grad of high school, phd thesis, A lanch tabatabaei university.

[22]Bandura, A. (1997). Self-efficacy: the exercise of control. USA: Englewood-cliffs, NJ: prentice hall.

[23]Pajares, Frank, Miller, M. David. (1994). Role of self-efficacy and self-efficacy beliefs in mathematical problem solving. Journal of educational psychology, Vol 86(2), Jun 1994, 193-203.

[24]Green, B. A. miller, R. B., Growson, H. M. Duke, B. L., \& akey, K. (2004). Predicting high school students' cognitive engagement and achievement: contributions of classroom perceptions and motivation. Contemporary Educational psychology, logy, 29-462-482.

[25]Pajares, F. \& Graham, L. (1999). Self- efficacy, motivation constracts, and mathematics performance of entering middle school students. Contemporary Educational Psychology. 24, 124-139.

[26] Kabiri, Masoud (2003). The role of self-efficacy in math achievement due to personal variables. Master's Thesis Teacher Training University.

[27]Tapola, a. , niemivirta, m. (2008)."the role of achievement goal orientations in student's perception of and preferences for classroom environment". british journal of educational psychology, 78, 291-312.

[28] Garcia, T., \& Pintrich, P.R. (1996). The effects of autonomy on motivation and performance in the college classroom. Contemporary Educational Psychology, 21, 477-486.

[29]Deci, E. L., Betley, G., Kahle, J., Abrams, L., \&Porac, J. (1981). When trying to win: Competition and intrinsic motivation. Personality and Social Psychology Bulletin, 7, 79-83.

[30]Deci. L, \& ryan, R. M. (1991). A motivational approach to self: integration in personality. In R. dienst bier (Ed.), Nebraska symposium on motivation: Vol. 38, perspectives on motivation (pp. 337-388). Lincoln, WE: university of Nebraska press. 
[31]Ryan, R. M., \& Grolnick, W. S.( 1986). Origins and pawns in the classroom: Self-report and projective assessments of individual differences in children's perceptions. Journal of Personality and Social Psychology, 50, 550-558.

[32] Atapour, Shahla (2001) Examine the relationship between academic achievement motivation of girls and boys schools in the city of Isfahan with family characteristics and personality of the academic year 2000

[33]Nasiri Fakhrosadat (2000) The effect of the factors affecting student achievement motivation branches of the vocational high school in the city of Sari 1999-2000 academic year. Master's thesis, University of Surrey.

[34]Motaghi, Khadijah (1997). Students investigate the causes of the failure of the new system in the cities of Sari, Babol and Ghaemshahr 1375-76 school year. Master's in mathematics, Islamic Azad University of Sari.

[35] Talebzadeh sani, hadi, kadivar, parvin. Investigate the relationship between moral reasoning and moral behavior metacognitive knowledge. Journal of Education; spring 2008, period 24, N 1. Page 7-32.

[36]Pajares, F. \& Miller, M. D. (1997). Mathematics Self-efficacy and mathematical problem solving: Implications of using varying forms of assessment. Journal of Experimental Education. 65, 213-228.

[37]Pajares, Frank, Miller, M. David. (1994). Role of self-efficacy and self-efficacy beliefs in mathematical problem solving. Journal of educational psychology, Vol 86(2), Jun 1994, 193-203.

[38] Abdi Nia, M. (1998). Evaluation of efficacy of goal orientation, self-regulated learning and academic achievement of students in third. Master's thesis, Tehran University.

[39] Kaviani, Maryam (1384). The relationship between thinking styles and self-efficacy and academic achievement of high school students. Master's thesis. Tehran Azad University.

[40]Zeinali Pour, Zandinia, Zarei (2009). General self-efficacy and academic students and its relationship with academic performance. Journal of Educational Psychology ninth numbers. The summer of 2009. 
[41]Kareshki, Hossein Mohseni, Nickchehreh, (2012). Motivation in teaching and learning (theory and applications), the first edition. Tehran: Avaye Nour.

[42] Kamali zarch, Mahmoud, kadivar, parvin, ghazi tabatabaei, Mahmoud and kiamanesh, alireza (2006). The role of efficacy data sources and personal qualities in self-efficacy and mathematics performance, 167-184.

How to cite this article:

Yahyazadeh F and Mohammadipour M. The role of interest, self-efficacy and academic self-regulation in predicting academic achievement of students of Islamic Azad University. J. Fundam. Appl. Sci., 2016, 8(4S), 2059-2075. 